\title{
Money-Income Relationships and the Exchange Rate Regime
}

\author{
TERRY C. MILLS and GEOFFREY E. WOOD
}

HE analysis recently elaborated in the monetary approach to the balance of payments literature demonstrates that the ability of a particular monetary authority to control its domestic monetary conditions depends crucially on two factors. The first relates to whether or not the country is the reserve currency center (the country whose money is held as international reserves by other countries); the second concerns the prevailing exchange rate regime.

As that body of analysis shows, the monetary authorities in non-reserve centers can fully control domestic monetary conditions only under a completely freely floating exchange rate regime. With pegged exchange rates, the authority's control over monetary conditions is limited by the extent to which they are willing to allow their exchange rate to change or their willingness to change their stock of international reserves. Otherwise, they can neither offset a monetary impulse from abroad nor affect nominal income by their own monetary actions.

The monetary approach to balance-of-payments analysis also indicates that, in contrast to the situation in non-reserve centers, the monetary authorities in the reserve center can influence monetary conditions both domestically and in non-reserve centers (by influencing worldwide monetary conditions) under a fixed exchange rate regime. Of course, they can infuence only their own monetary conditions when exchange rates are floated. ${ }^{1}$

NOTE: Terry C. Mills is a lecturer in econometrics at the University of Leeds, England. This paper was in large part written while Geoffrey E. Wood, Senior Lecturer in Banking and International Finance at the City University, London, England, was visiting the Federal Reserve Bank of St. Louis. the monetary approach to balance-of-payments analysis has a long history, dating certainly from David Hune's essay "Of the Balance of "Trade" first published in 1752, which can be found in David Hume: Writings on Economics, ed. Eugene Rotwein (Madison, Wise, The University of Wisconsin Press, 1970), pp. 60-77. The modern rentegration of monetary and balance-of-payments analysis was pioneered in James Edward Meade, The Balance of Payments (London: Oxford University Press, 1951), and a sample of recent work is contained in Jacob $A$. Frenkel and Harry G. Johnson, eds., The Monetary Approach to the Balance of Payments (London: George Allen and Unwin Ltd., 1975).
The importance of utilizing this approach to assess the relationship between money and income is highlighted by the apparently contrasting results obtained in recent studies of the money-income relationship for the United States and the United Kingdom. These studies used the Sims test, which is designed to determine the existence and direction of causality between two variables. ${ }^{2}$ That test is based upon the assumption that if one variable leads another (temporally), it can cause movements in that other variable, while if one variable follows the other, no such possibility exists. ${ }^{3}$

In terms of a money stock variable (M) and an income variable $(Y)$, if changes in $M$ cause changes in $\mathrm{Y}$, then a regression of current $\mathrm{M}$ on past, present, and future values of $Y$ should show significant coefficients for future, and perhaps present, values of $\mathrm{Y}$, but insignificant coefficients on past values of Y. Further, if changes in $M$ cause changes in $Y$, regressing $Y$ on past, present, and future values of $M$ should yield significant coefficients on past, and perhaps present, values of $M$, and insignificant coefficients on future values of $M$.

Sims applied this test to the United States and found that changes in monetary growth caused changes in the growth rate of income.* However,

"Christopher A. Sims, "Money, Income, and Causality," American Economic Retiew (September 1972), pp. 540-52.

aC. W. I. Granger and Paul Newbold, Forecasting Economic Time Series (New York: Academic Press, 1977), p. 225, suggest that in discussing tests of the types sef out here, it may be preferable to replace the word "cause" with the phrase "temporally related," as these tests do not necessarily satisfy the nomal philosophical criteria for establishing causality, But as $H$. Feigl states in, "Notes on Causality" in $H$. Feigl and M. Broadbeck, eds., Readings in the Philosophy of Science (New York: Appleton-Century-Crofts, Inc., 1953), p. 408, "The clarified (purified) concept of causality is de" fined in terms of predictability according to a law (or more adequately, according to a set of laws)." This suggests that the word "cause" may be permissible in the present context in view of the existence of a predictive model which underlies the analysis. An extensive discussion of these issues can be folnd in Arnold Zellner, "Causality and Econometrics" (Paper presented at University of Rochester-Camegie Mellon University Conference, University of Rochester, April 1978).

4Sims, "Money, Income, and Causality." 
when Williams, Goodhart, and Gowland applied this test to data from the U.K. economy for the U/1958 III/1971 period, they found no clear evidence of causality in either direction. ${ }^{5}$ This result conflicts not only with Sims' results for the United States, but also with other findings, which demonstrate a well determined money-income relationship for the United Kingdom, derived by estimating money demand equations. ${ }^{6}$

The results can, however, be reconciled by recog. nizing the significance of the exchange rate regime for the influence of money on income.

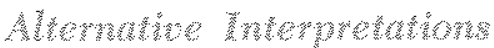

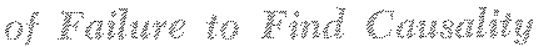

The failure of Williams, Goodhart, and Gowland to find a one-way relationship between money and income by means of the Sims test can bear more than one interpretation. It can mean that no causal relationship exists. Alternately, it can mean that the money-income causal relationship varied within their data period. On some occasions, when the monetary fluctuation either originated from the reserve center, was in line with a monetary fluctuation in the reserve center, or was accommodated by an exchange rate change, money influenced income in the United Kingdom. At other times, the monetary stimulus, of domestic origin, led to balance-of-payments pressure which induced the monetary authorities to reverse

\footnotetext{
5David Williams, C. A. E. Goodhatt, and D. H. Gowland, "Money, Income, and Causality: the U.K. Experience," American Economic Review (June 1976), pp. 417-23.

well determined money demand functions for the United Kingdom have been found by, among others, L. D. D. Price, "The Demand for Money in the United Kingdorn: A Further Investigation" Bank of England Quarterly Bulletin (March 1972), pp. 43-55, and Michael I. Hamburger, "The Demand for Money in an Open Econony: Germany and the United Kingdom" Jotunal of Monetary Fconomics (January 1977), pp. 25 40. In his paper, "The Demand for Money in the United Kingdom: Experience Since 1971," Bank of England Ouarterly Bulletin (Septenber 1974), pp. 284m305, Graham Hacche found that the fit of previously estimated MI demand equations for the United Kingdom appeared to deteriorate towards the end of 1971 . This might perhaps suggest that the money-income relationship is not particularly stable in the United Kingdom, However, a more recent study, $R$, $T$, Coghlan, "A Transactions Demand for Money," Bank of England Ouarterly Bulletin (March 1976), p. 51, found that “... the evidence would now appear to support the existence of a stable demand-for-money function. . . " It is suggested in Michael I. Hamburger and Geoffrey E. Wood, "Interest Rates and Monetary Policy in Open Economies" (Paper presented at the Allied Social Science Association's Anmual Meeting, New York, December 26-30, 1977) that the deterioration in fit which Hacche fonnd may have been dae to a policy-indnced change in the structure of financial markets.
}

their previous monetary policy with sufficient rapidity that the initial monetary stimulus did not persist long enough to have a discernible effect on income. If this occurred, no causality from money to income would be observed. Further, when the U.K. monetary authorities were pegging the exchange rate and resisting interest rate movements - as they were for a substantial part of the data period used by Williams, Goodhart, and Gowland - an exogenous income fluctuation would induce an accommodating monetary response. ${ }^{7}$

In other words, within their data period, on some occasions money influenced income; on some occasions income influenced money; and on other occasions monetary actions were so quickly reversed that there was no time for them to influence income. The Williams, Goodhart, and Gowland result could therefore have been produced by their carrying out their test over what was a collection of subperiods, heterogeneous with respect to the causal relationship between money and income, as if the collection was actually one homogeneous data set. (It should be emphasized that the nature of the test, in combination with U.K. exchange rate policy, gave them no alter native in the data set they used..$^{8}$ )

\footnotetext{
${ }^{7}$ An analysis of how, in these conditions, monetary policy can only accommodate income fluctuations can be found in Robert A. Mundell, "The Appropriate Use of Monetary and Fiscal Policy for Internal and External Stability," International Monetary Fund Staff Papers (March 1962), pp. 70-79. A description by the U.K. monetary authorities themselves of their attitude towards interest rates can be found in "Key Issues in Monetary and Credit Policy" a speech by $L$, $K$. (now Lord) O'Brien, then Governor of the Bank of England, given at an international banking conference at Munich on May 28, 1971, and printed in the Bank of England Quarterly Bulletin (June 1971), pp. 195 98. Williams et al. do not say explicitly that they consider exchange rate policy and interest rate policy to have produced their restuts. Their article does, however, contain a summary of the conduct of U.K. monetary policy similar to that given above, and concludes with a sentence which can readily bear the interpretation that they believe that, as a consequence of seeking other objectives, the authorities lost control over U.K. monetary conditions. "This suggests, perhaps, a more complicated causal relationship between money and incomes in which both are determined simultaneously."
}

It is conceivable in principle that the results of Williams et al. were produced because the adjustment of income to money was complete within the unit of observation. But that does not seem a reasonable explanation in the present case, as it wouk imply a lag of about onemeighth of that found by other studies. These studies are surveyed in David Laidler, "Inflation in Britain: A Monetarist Perspective," American Economic Review (September 1976), pp. 485-500.

8A ruost usetul analysis of economic policy in the United Kingdom, highlighting the relationship between the conduct of nonetary policy and the state of the balance of payments, can be found in Dietrich K. Fausten, The Consistency of British Balance of Payments Policies (London: Macmillan, 1975 ) 
Therefore, the conflict between the results of Williams, Goodhart, and Gowland and the finding of a stable money demand function in the United Kingdom can be reconciled by the argument that the causal relationship between money and income in their data period should be, as indeed they found it, not clear cut in either direction. The relationship would vary with both the origin of the monetary impulse (whether or not it came from abroad), and the effect it was allowed to have on the exchange rate or the United Kingdom's stock of international reserves.

Furthermore, the analysis also suggests why Sims encountered no such interpretation problems. He applied the test to the United States, which was the reserve center in his data period, and therefore produced results consistent with both United States money demand studies and more general studies such as Milton Friedman and Anna Jacobson Schwartz, A Monetary History of the United States, 1867-1960 (Princeton: Princeton University Press, 1963). ${ }^{9}$

The empirical findings of Sims and of Williams, Goodhart, and Gowland are consistent with the above analysis of the importance of both the exchange rate regime and how it influenced the behavior of policymakers in the interpretation of the money-income relationship. They do not, however, yield very strong support for this proposition, since the implication from the monetary approach to balance of payments was that when applying the Sims test, the exchange rate regime should not affect the result for the United States and that the test should reveal no clear cut relationship for the United Kingdom. It is strongly desirable that the analysis be tested on some other data set, for which it yields a different and more clear-cut prediction. ${ }^{10}$

\footnotetext{
'Questions have been raised about Sims' findings, but his lindings seem to be fairly generally accepted; see, for example, Yash P. Mehra. "An Empirical Note on Some Monetarist Propositions," Southern Economic Journal (July 1978), pp. 154-67. A discussion and assessment of the reasons underlying the questioning of Sims findings can be found in $\mathbf{G}$. William Schwert, "Tests of Causality; The Message in the Innovations" (Working Paper Series No. GPB77-4, Graduate School of Management, University of Rochester, 1977).

10Buthord H. Putnam and D. Sykes Wilford, "Money, fucome, and Causality in the United States and the United Kingdom: A Theoretical Explanation of Different Findings," American Economic Review (June 1978), pp. 423-27, use a simple formal model, based upon the monetary approach to balance-of-payments analysis, to develop a reconciliation of the Sims and Williarns et al. restlts which is similar to that suggested above. However, their reconciliation depends on the assumption of very rapid arbitrage of prices inter nationally. Without that assumption, which is inconsistent with firdings in John Williamson and Geoffrey $\mathrm{E}$. Wood, "The British Inflation, Indigenous or Imported?" American
}

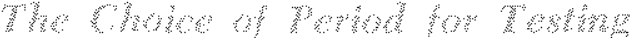

It might appear that data from any country, ex cept the United States, would be suitable so long as it was from the period of floating exchange rates since the breakdown of the Bretton Woods system in 1971-72. There are, however, two difficulties with such a choice. First, the period is rather short for the testing of a money-income relationship by the Sims method. Second, the float has not been free from official exchange market intervention, so the results of a causality test would be predicted to remain ambiguous. Nor can any suitable data be obtained prior to the breakdown of the Bretton Woods agreement, for virtually no country pursued an unvarying exchange rate policy throughout that period.

There is, however, one set of data, although certainly not recent, which is suitable for the present test. It consists of U.K. data for the period 1870 to 1914, the heyday of the gold standard and fixed exchange rates. This episode is long enough for the testing of a money-income relationship, the exchange rate was pegged throughout the period, and the focus of monetary policy was the condition of the balance of payments.11 Hence, the situation corresponds exactly to the fixed exchange rate model analyzed by, for example, R. A. Mundell, in which monetary policy cannot affect income, but rather income fluctuations produce accommodating monetary flows. ${ }^{12}$

Accordingly, an application of the Sims causality test to this period, if it found that income led money, wotld support the proposition that the exchange rate regime is crucial to the interpretation of the results of a two variable test for the causal relationship between money and income.

Economic Review [September 1976], pp. 520-31, one must take account of the interaction of the attitudes of the monetary authorities with the exchange rate regime, in the mamer done above, before the findings of Sims and Willians et al. can be reconciled. Further, Putnam and $W$ i1ford's paper includes no empirical work.

11Some countries had their exchange rates pegged to sterling. so the system was not the pure gold standard of theory. The Bank of England did, however, act by gold standard rules and adjusted monetary policy as indicated by the U.K. balance of payments. A brief and vivid description of the conduct of U.K. monetary policy in this period can be found in Noman Macrae, "Towards a Keynesian Friedmanism," The Economist, June 17-23, 1978, po, 37 41, and a detatled analysis is given in Alec $\mathrm{G}$. Ford, The Gold Standard, 1880-1914: Britain and Argentina (Oxford: Clarendon Press, 1962).

${ }^{12}$ See R. A. Mundell, "The Appropriate Use of Monetary and Fiscal Policy," That would also be the prediction of Putnam and Wilford's nodel, "Money, Income, and Causality," if one relaxed their assumption of very rapid price arbitrage. 


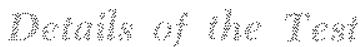

The relationship between nominal income and nominal money was assumed to be linear in levels of the variables; identical results were found when the estimation procedure was repeated with the variables in logarithmic form. ${ }^{13}$

The number of future and past lags included in the regressions was determined by the form of the data. The $M$ series relates to year-end stock whereas the $Y$ series relates to a flow throughout the year. Thus the income observation associated with year $t, Y_{t}$, must be regarded as leading the corresponding money observation, $\mathrm{M}_{\mathrm{t}}$, by approximately six months. Therefore, when regressing $\mathrm{M}$ on $\mathrm{Y}$, the contemporaneous variable $Y_{t}$ must be regarded as a past lag, whereas when regressing $\mathrm{Y}$ on $\mathrm{M}$, the contemporaneous variable $M_{t}$ must be considered as a future lag.

Incorporating that point and considering the degrees of freedom available led to the specification of the following regression models.

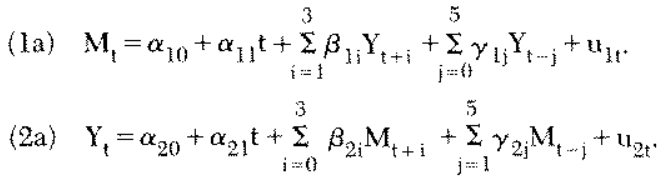

In terns of the coefficients of these models, unidirectional causality from $\mathrm{Y}$ to $\mathrm{M}$ requires that

$$
\begin{aligned}
\beta_{1} & =\left[\beta_{11}, \beta_{12}, \beta_{13}\right]=0 \\
\gamma_{1} & =\left[\gamma_{11}, \ldots, \gamma_{15}\right] \neq 0 \\
\beta_{2} & =\left[\beta_{20}, \ldots, \beta_{23}\right] \neq 0 \\
\text { and } \quad \gamma_{2} & =\left[\gamma_{21}, \ldots, \gamma_{25}\right]=0 .
\end{aligned}
$$

Unidirectional causality from $\mathrm{M}$ to $\mathrm{Y}$, on the other hand, requires that

$$
\begin{aligned}
\beta_{1} & \neq 0 \\
\gamma_{1} & =0 . \\
\beta_{2} & =0 \\
\gamma_{2} & \neq 0
\end{aligned}
$$

The first set of conditions would show $\mathrm{Y}$ temporally leading $M$ and the second would show $M$ temporally leading $\mathrm{Y}$.

\footnotetext{
13. As nominal income from 1870 to 1914 we used GNP, and as money for that period we used a series calculated by Shizuya Nishimura, The Decline of Inland Bills of Exchange in the London Money Market, 1855 -1913 (London: Cambridge University Press, 1971). This latter series is the closest approximation to current $\mathrm{Ml}$ which is avalable for our data period; we are indebted to Professor Nishimura for his extensive discussion of the series with us.
}

The actual estimation and testing procedures are outlined in the Appendix, while the resulting estimates and test statistics, accompanied by related stmmary statistics, are given in Table I. Columns (1b) and (2b) show the results obtained by estimating the two equations under the assumption that the errors were generated by a first order autoregressive process, with $\rho$ denoting the estimate of the coefficient of that process. Columns (1c) and (2c) show the results obtained from estimating the equations under the restrictions $\beta_{x}=0$ and $\beta_{2}=0$ respectively, while columns (1d) and (2d) show the results obtained under the restrictions $\gamma_{1}=0$ and $\gamma_{2}=0$. The variable $L$ denotes the log likelihood of each estimated equation and $\mathrm{T}$ denotes the number of observations. The $\chi^{2}$ statistics derived from these log likelihoods test the above restrictions as follows: $X_{i e}^{2}$ tests the null hypothesis $\beta_{i}=0$, and $\chi_{\text {id }}^{2}$ tests the null hypothesis $\gamma_{i}=0$. (See Appendix for further details.)

From the values of $X_{1:}^{2}$ and $X_{2 d}^{2}$, we cannot reject the null hypotheses $\beta_{1}=0$ and $\gamma_{2}=0$ at any conventional significance level, whereas from the values of $X_{2 \mathrm{C}}^{2}$ and $X_{\mathrm{id}}^{2}$, the null hypotheses $\beta_{2}=0$ and $\gamma_{1}=0$ can be rejected at the .005 and .05 levels of significance respectively. In view of the conditions required for the existence of unidirectional causality, these results imply that there is unidirectional causality between $\mathrm{Y}$ and $\mathrm{M}$, the direction of causality being from $\mathrm{Y}$ to $\mathrm{M}$. In other words, fluctuations in $\mathrm{Y}$ induce fluctuations in $M$. There is no evidence to suggest that there is any causality running from $\mathrm{M}$ to $\mathrm{Y}$.

Although the estimated regression coefficients show that the lag distributions are rather loosely determined - no doubt a consequence of the lack of any prior restrictions on their shape - one important feature emerges. The largest and most significant coefficients appear on the contemporaneous independent variables in all regressions, on the one period past lag variable in the $M$ on $Y$ regressions and on the one period future lag variable in the $\mathrm{Y}$ on $\mathrm{M}$ regressions. In view of the data considerations discussed previously, this suggests that income led money by 6 to 18 months.

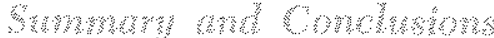

It has been argued that, when interpreting the results of the Sims test for causality, it is essential to consider the expected effects of exchange rate policy if the test is being used to examine the relationship between money and income. The results of both the 
Table 1

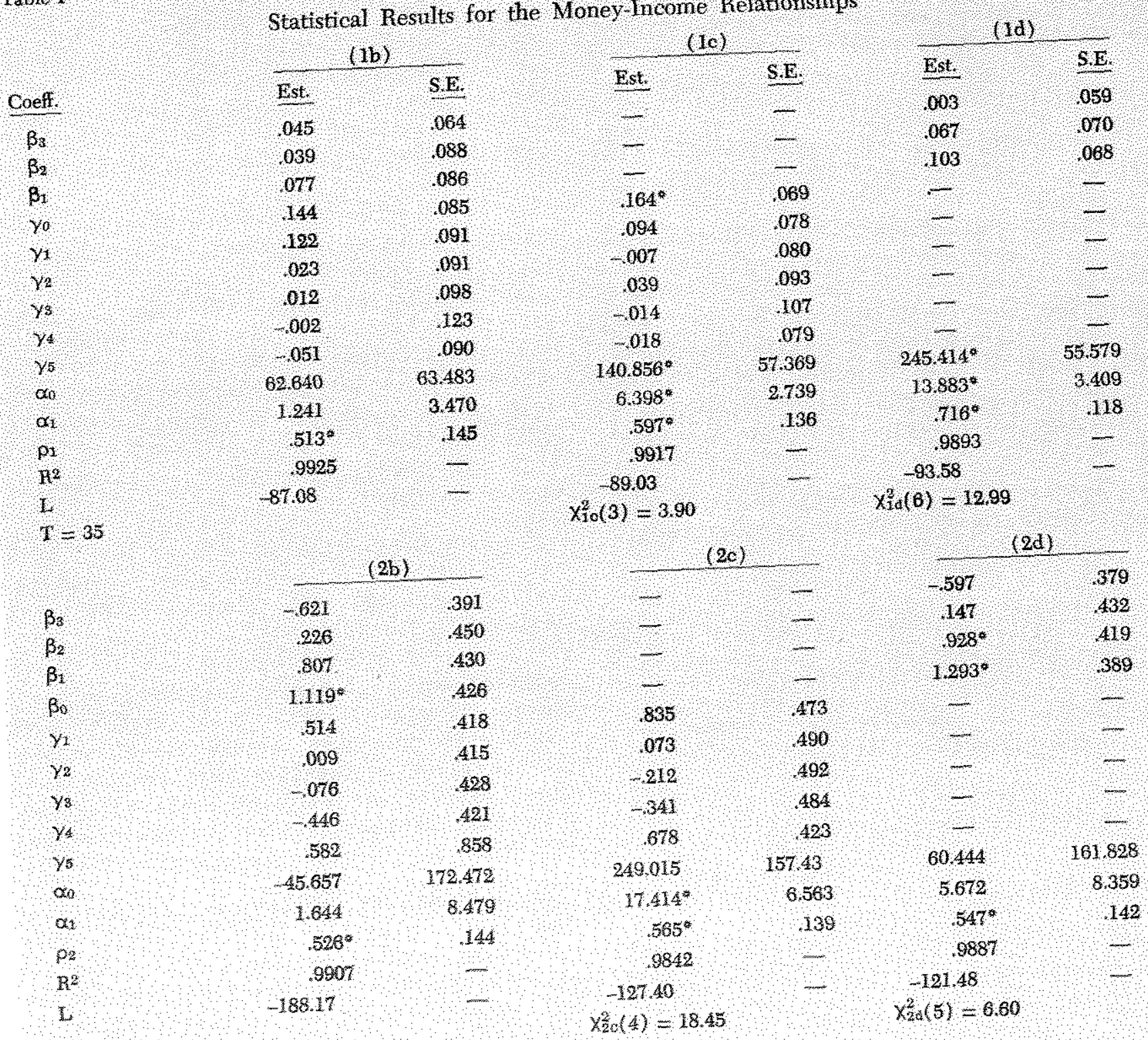

SW $=$ Sondart errors

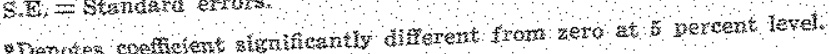

Sims study of the United States and the Willams, Goodhat, and Gowland study of the United Kingdon are consistent with this approach, but neither sudy was well suited to testing this proposition. Accordingly, the Sins test was used to analyze the money-income relationship for the United Kingdom during a period when a different relationship from that found by either Sims or Wiliams, Goodhart, and Gowland was predicted. The results were found to confirm the importance of assessing the impact of exchange rate policy.
Further, these results seem to resolve the apparent inconsistency between the results of Sims-type studies of the United Kingdom in the Bretton Woods era, and those of money demand studies. It appears that the exchange rate regime maked the underlying money-income relationship from tests of the Sims type. Therefore, the results from money demand studies are more userul in revealing the money. incone relationship for the United Kingdom (and presumably other such countries) in the Bretton Hoods period than are Sins-type resuls. 


\section{APPENDIX}

The basic equations to be estimated are

(1a)

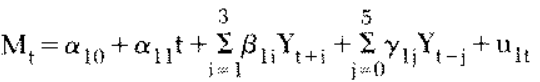

$$
\begin{aligned}
& \text { (2a) } Y_{t}=\alpha_{20}+\alpha_{21}{ }^{t}+\sum_{i=1 j}^{3} \beta_{2 i} M_{t+i}+\sum_{j=1}^{5} \gamma_{2 j} M_{t-j}+u_{2 t} \\
& t=1,2, \ldots, T \text {. }
\end{aligned}
$$

However, as the precise use of significance tests on groups of coefficients is required, it is important that the errors in the regressions be serially uncorrelated. Althongh the inclusion of a linear time trend in the equations will partially account for serial correlation, the error terms were assumed to be generated by first order autoregressive processes, that is:

(3) $\mathrm{u}_{1 \mathrm{f}}=\rho_{1} \mathrm{~b}_{\mathrm{l}}, \mathrm{t}-1+\epsilon_{1 \mathrm{l}}$

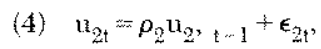

with $\epsilon_{11}$ and $\epsilon_{21}$ assumed to be independently normally distributed random variables with zero means and constant variances. This assumption led to the use of maximum likelihood estimation methods rather than conventional regression techriques. Equations (la) and (2a) were transformed using (3) and (4) to obtain

$$
\begin{aligned}
& M_{i}^{*}=\alpha_{10}\left(1-\beta_{1}\right)+\alpha_{11} t^{\circ}+\sum_{i=1}^{3} \beta_{1 i} Y^{\circ}{ }_{1+i}+\sum_{j=0}^{5} \gamma_{1 j} Y^{\circ}{ }_{1 \ldots j}+\epsilon_{1 t}
\end{aligned}
$$

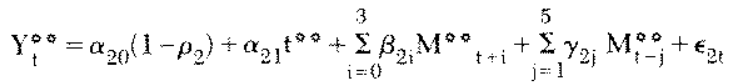

where $\mathrm{M}_{t}^{\infty}=\mathrm{M}_{\mathrm{E}}-\rho_{1} \mathrm{M}_{1 \ldots 1}, \mathrm{M}^{\rho \circ}=\mathrm{M}_{1}-\rho_{2} \mathrm{M}_{t \ldots 1}$, etc.

The maximum likelihood (ML) estimate of $\rho_{i}, \mathrm{i}=1$ or 2 , was oftained by minimizing

$$
\dot{\sigma}_{\mathrm{i},}^{2}\left(\rho_{\mathrm{k}}\right) /\left(1-\rho_{\mathrm{i}}^{2}\right)^{1 / \mathrm{q}}
$$

where $\dot{\sigma}_{\mathrm{i}}^{3}\left(\rho_{\mathrm{i}}\right)=\mathrm{S}_{\mathrm{in}}\left(\rho_{\mathrm{i}}\right) / \mathrm{T}, \mathrm{S}_{\mathrm{b}}\left(\rho_{\mathrm{l}}\right)$ being the residual sum of squares from the regression of equation (ib), $i=1$ or 2, associated with a given value of $\rho_{i}{ }^{\prime}$. This minimization was actually accomplished by searching over the admissible range of $\rho_{i},(-1,1)$. ML estimates of the other parameters of (ib) were obtained as the coefficients of the regression associated with the ML estimate $\hat{\rho}_{\mathrm{it}}$.

Under the hypotheses $\beta_{1}=0$ and $\beta_{2}=0$, the following restricted models were obtained:

\footnotetext{
'See Phoebus J. Dhrymes, Distributed Lags: Problems of Estimation and Formtalation (San Franciseo; Folden-Day, 1971), pp. 64-70.
}

(1c) $\mathrm{M}_{t}^{\sharp}=\alpha_{10}\left(1-\rho_{1}\right)+\alpha_{11} t^{*}+\sum_{j=0}^{5} \gamma_{1 j} \mathrm{Y}_{i \cdots j}^{\mathrm{s}}+\epsilon_{1 \mathrm{t}}$

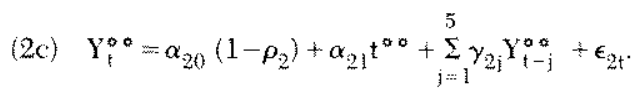

Again, ML estimates of the parameters of these models were obtatned by minimizing

$$
\dot{\sigma}_{i \in}^{2}\left(\rho_{j}\right) /\left(1-\rho_{i}^{2}\right)^{1 / T}
$$

and estimating the coefficients if the regression associated with $\dot{\rho}_{\mathrm{i} \kappa}$.

The above hypotheses were tested by constructing the appropriate likelihood ratio test. Since the maximum log likelibood of equations (ib) and (ic), denoted $L_{i b}$ and $L_{\text {ijc }}$, are

$$
\mathrm{L}_{\mathrm{i} b}=\text { Constant }-\frac{\mathrm{T}}{2} \ln \left[\frac{\hat{\sigma}^{2}\left(\rho_{\mathrm{ib}}\right)}{\left(1-\hat{\rho}_{\mathrm{i} i}^{2}\right)^{1 / T}}\right]
$$

and $L_{\mathrm{ic}}=$ Constant $-\frac{\mathrm{T}}{2} \ln \left[\frac{\hat{\sigma}^{2}\left(\rho_{\mathrm{ic}}\right)}{\left(1-\hat{\rho}_{\mathrm{jc}}^{2}\right)^{1 / \mathrm{T}}}\right]$

respectively, then the statistic

$$
x_{i c}^{2}=2\left(\mathrm{~L}_{\mathrm{i} b},-\mathrm{L}_{\mathrm{ic}}\right)
$$

is asymptotically distributed as chi square with $k_{i}$ degress of freetom, $k_{1}$ being the number of coefficients in $\beta_{\mathrm{l}}{ }^{2}$ Values of this statistic greater than $\chi_{\alpha}^{2}\left(\mathrm{k}_{i}\right)$ will reject the null hypothesis $\beta_{1}=0$ at the $(1-\alpha)$ level of significance.

A similar approach was taken in testing the hym potheses $\gamma_{1}=0$ and $\gamma_{2}=0$. Here the restricted models were given by

$$
\begin{aligned}
& \text { (1d) } \mathrm{M}_{\mathrm{i}}^{\circ}=\alpha_{10}\left(1-p_{1}\right)+\alpha_{11} \mathrm{t}^{*}+\sum_{\mathrm{i}=1}^{3} \beta_{1,} \mathrm{Y}_{\mathrm{t}, \mathrm{s}}^{*}+\epsilon_{1 \mathrm{t}} \\
& \text { (2d) } \quad \mathrm{Y}_{t}^{\circ}=\alpha_{20}\left(1-\rho_{2}\right)+\alpha_{21} \mathrm{t}^{\infty-\alpha}+\sum_{i=0}^{3} \beta_{2 i} \mathrm{M}_{1+1}^{00}+\epsilon_{2 ;}
\end{aligned}
$$

ML estimation of these models leads to the test statistic

$$
x_{\mathrm{id}}^{2}=2\left(\mathbf{L}_{\mathrm{it}, \mathrm{i}} \mathrm{L}_{\mathrm{id}, \mathrm{d}}\right)
$$

values of which greater than $\chi_{\alpha}^{2}\left(h_{1}\right)$, where $h_{j}$ is the number of coefficients in $\gamma_{1}$, lead to the rejection of the null hypothesis $\gamma_{i}=0$ at the $(1-\alpha)$ level of significance.

\footnotetext{
"See Dhrymes, "Distributed Lags," pp. 83-84.
} 